\title{
Thermo-Hydro-Mechanical Effects in Clay Host Rocks for Radioactive Waste Repositories
}

\author{
Jean Sulem $\cdot$ Xiang-Ling Li
}

Received: 30 May 2013/Accepted: 4 June 2013/Published online: 15 June 2013

(C) Springer-Verlag Wien 2013

In all nuclear power-generating countries, the management of spent nuclear fuel and long-lived radioactive waste is an important environmental issue. Disposal in deep clay geological formations is one of the promising options recommended at the international level. In this concept of the geological disposal system, the host clay formation is considered as a principal barrier on which rests the fulfilment of key safety functions. Hence, preventing unnecessary damage to the host formation is one of the objectives of repository design. A proper evaluation of the excavation-damaged zone (EDZ) in the host formation is, thus, an important issue for the long-term safety of underground disposal.

As a side effect of radioactive decay, vitrified high-level wastes and spent fuel release a significant amount of heat, even after several decades of cooling in surface facilities. The influence of the thermal load generated by the radioactive waste on the performance of the disposal system is particularly important, since the early transient thermohydro-mechanical (THM) perturbation might be the most severe impact on the repository system on a large spatial scale and in a relatively short period of time. Assessing the consequences of the thermal transient on the performance of the disposal system was the main objective of the TIMODAZ European project.

Between 2006 and 2010, the TIMODAZ project (Thermal Impact on the Damaged Zone Around a Radio-

\section{J. Sulem ( $\square)$}

UR Navier-CERMES, Ecole des Ponts Paris Tech, IFSTTAR, CNRS, Université Paris-Est, Marne-la-Vallée, Paris, France e-mail: jean.sulem@enpc.fr

\section{X.-L. Li}

European Underground Research Infrastructure for Disposal of Nuclear Waste in Clay Environment (EURIDICE), 2400 Mol, Belgium

e-mail: xli@sckcen.be active Waste Disposal in Clay Host Rocks, http:// www.timodaz.eu/), which gathered 15 partners from eight countries, has investigated the coupled THM effects in clay formations that are being studied as potential host rocks for the geological disposal of radioactive waste. Three types of clay and clay rocks corresponding to the three potential host sites for the Belgian, Swiss, and French disposal facilities were investigated: the Boom Clay (Belgium), the Opalinus Clay (Switzerland), and the Callovo-Oxfordian argillite (France).

The project focused on the combined effect of the EDZ and the thermal output from the waste on the repository host rock. The influences of the temperature increase on the evolution of the EDZ as well as the possible additional damage created by the thermal load were also the main issues of the study. The chemical evolution as well as its interaction with the THM processes around the underground repository were also addressed in the project, but to limited extent. Intensive experimental (laboratory and in situ in underground research laboratories) and numerical studies have been performed in order to better understand the impact of the coupled THM processes on the long-term evolution and safety of repositories.

On 6-7 February 2012, an international post-TIMODAZ workshop was organized at Mont Terri Rock Laboratory, Switzerland, in order to present the main TIMODAZ results, and also other contributions in the area of the THM analysis of nuclear waste disposal systems and to foster informal discussions and exchanges on THM issues in clay host rocks. This special issue includes 15 selected papers which expand on the technical contributions presented at this International post-TIMODAZ workshop. The submitted papers underwent a complete review process following the publication rules of Rock Mechanics and Rock Engineering under the supervision of the guest editors. 